\title{
Increased aldosterone in patients with metabolic syndrome; an additional risk factor
}

\author{
Mohamed Abdou ${ }^{1 *}$, Mohamed Sherif AbdEIGawad ${ }^{2}$ and Sahar AlSayed Mohamed ${ }^{3}$ \\ *Correspondence: mhmdabdou232@yahoo.com \\ ${ }^{1}$ Cardiology Department, Zagazig University, Egypt . \\ IInternal Medicine Department, Mansoura University, Egypt. \\ ${ }^{3}$ Clinical Pathology Department, Mansoura University, Egypt.
}

\begin{abstract}
Background: Patients with metabolic syndrome (MSyn) are prone to increased cardiovascular morbidity and mortality, although the underlying mechanisms including plasma aldosterone (PA) are not yet fully known.

Aim: Evaluate the association of PA with the MSyn and each of its components.

Methods: 46 patients with MSyn and 25 healthy subjects as a control were subjected to measurements of BMI, waist circumference, office BP \& HR, 24-hour BP monitoring, fasting blood sugar (FBS), lipid profile, serum sodium \& potassium, serum insulin, insulin resistance calculation, plasma renin activity (PRA) and PA concentrations.

Results: PA concentrations, but not PRA, were significantly higher in MSyn patients (P 0.001, P 0.770 respectively).HR was significantly increased in MSyn patients compared to controls (P 0.024).There were significant positive correlation between PA level and BMI, waist circumference, SBP, DBP, s.triglycerides, FBS and insulin resistance $(\mathrm{r} 0.947, \mathrm{P}<0.0001, \mathrm{r} 0.829$, $\mathrm{P}<0.0001, \mathrm{r} 0.885, \mathrm{P}<0.0001, \mathrm{r} 0.831, \mathrm{P}<0.0001, \mathrm{r} 0.611, \mathrm{P}<0.0001, \mathrm{r} 0.851, \mathrm{P}<0.0001, \mathrm{r} 0.712, \mathrm{P}<0.0001$ respectively). A significant negative correlation was present between PA level and HDL-C $(\mathrm{r}-0.443, \mathrm{P}<0.002)$. BMI \& SBP were the only independent factors affecting PA level by regression analysis. In contrast to PRA, PA tended to increase with an increasing number of MSyn risk factors. In conclusion, PA is associated with MSyn and its components suggesting the link between aldosterone and several cardiovascular risk factors and this may address the possible beneficial effects of aldosterone blockade in those patients with MSyn.
\end{abstract}

Keywords: Metabolic syndrome, plasma aldosterone, plasma renin activity

\section{Introduction}

The metabolic syndrome (MSyn) represents a clustering of several cardiovascular risk factors, which include hypertension, dyslipidemia (low high-density lipoprotein (HDL) cholesterol and elevated triglycerides), abdominal obesity, glucose intolerance, and a proinflammatory and prothrombic state [1].

It is a cause for public health concern and its prevalence has increased over time. In the National Health and Nutrition Examination Survey (NHANES) cohort, the prevalence of MSyn between 1988 and 1994 was $29.2 \%$ and it reached $34.6 \%$ between 1999 and 2002 [2].

Patients with MSyn are associated with a 2-fold increase in cardiovascular outcomes and a 1.5 -fold increase in all-cause mortality, although the underlying mechanisms responsible for these associations are not yet fully known [3].

Aldosterone is a mineralocorticoid hormone classically involved in sodium balance regulation. Many recent studies involve aldosterone in the pathogenesis of the cardiometabolic syndrome $[2,4,5]$, although this relationship is complex and not well established, there is some evidence that different factors could act on it such as insulin resistance, renin-angiotensinaldosterone system, oxidative stress, sodium retention and volume overload, increased sympathetic activity, levels of free fatty acids, or inflammatory cytokines and adipokines [5].

The aim of this study was to measure plasma aldosterone concentrations in patients with MSyn, and to evaluate its associations with each component of MSyn.

\section{Subjects and methods \\ Patients}

Forty six patients with MSyn were selected using a standard definition of the MSyn based on National Cholesterol Education Program-Adult Treatment Panel III (NCEP-ATP III) criteria [6].

\section{Subjects with 3 or more of the following components were included in the study: \\ 1) Waist circumference $>102 \mathrm{~cm}$ in men and $>88 \mathrm{~cm}$ in women. \\ 2) Triglycerides $\geq 150 \mathrm{mg} / \mathrm{dl}$. \\ 3) HDL-cholesterol $<40 \mathrm{mg} / \mathrm{dl}$ in men and $<50 \mathrm{mg} / \mathrm{dl}$ in women. \\ 4) Ambulatory blood pressure $\geq 130 / 85 \mathrm{mmHg}$. \\ 5) Fasting blood glucose $\geq 110 \mathrm{mg} / \mathrm{dl}$.}

Exclusion criteria were the presence of the following: Patients with more than stage-I HTN or on antihypertensive or lipid lowering medications, diabetes mellitus, known renal, hepatic, or immunologic disorders, obesity secondary to hypothyroidism 
or Cushing's disease, severe debilitating disease, malignancy and pregnancy or lactation.

\section{Control}

Twenty five healthy, age-and sex-matched subjects were taken as a control group.

\section{Methods}

The study protocol was approved by the local ethic committee. All subjects gave written informed consent to participate in the study and the investigations conformed to the principles outlined in the Declaration of Helsinki [7].

\section{All subjects were recommended to consume a diet with a normal amount of salt and were subjected to the followings: \\ Thorough history and clinical examination \\ Standardized anthropometric measurements included height, weight, body mass index (BMI), waist circumferences were done. \\ - Body weight and height were measured with the patient in light clothes without shoes to the nearest $0.5 \mathrm{~kg}$ and $0.5 \mathrm{~cm}$. \\ - BMI was calculated by the formula: body weight (kg)/ height $\left(\mathrm{m}^{2}\right)$. \\ - Waist circumference was measured horizontally in quiet expiration, to the nearest $0.1 \mathrm{~cm}$, directly on the landmarked skin with a flexible, inelastic measuring tape with a tension meter attached. The measure was taken at the highest point of the iliac crest $[\mathbf{8 , 9}]$. \\ - Blood pressure (BP) and heart rate were measured with the patient seated, after a 5-min rest period. Two BP measurements with a mercury sphygmomanometer were obtained at 5-min intervals, and then averaged.}

\section{Standard 12-lead resting electrocardiography (ECG) Ambulatory BP monitoring (ABPM)}

24-hour BP monitor was set in place using a continuous blood pressure device (model 90207-30, Spacelabs Inc, Redmond, WA, USA). The device was placed on the non-dominant upper limb of the patient and was programmed to record $\mathrm{BP}$ readings every 30 minutes during daytime and every 60 minutes during nighttime.

A satisfactory number of readings were obtained from all subjects in the study and mean 24-hour systolic BP, diastolic $\mathrm{BP}$ readings, and heart rate as well were then obtained.

\section{Laboratory investigations Samples collection}

Fasting blood samples were collected while the patient was supine and had rested for $20 \mathrm{~min}$ and delivered into 2 tubes. Five $\mathrm{ml}$ of them was collected in K2EDTA-containing tubes and the samples were centrifuged for 5 minutes at $3000 \mathrm{rpm}$ at $4^{\circ} \mathrm{C}$. Plasma was stored at $-70^{\circ} \mathrm{C}$ until analysis of plasma renin activity (PRA) and plasma aldosterone (PA) concentration.
The rest of blood sample was collected in biochemical tube to obtain serum. The serum samples were obtained by centrifuging blood samples at $3000 \mathrm{rpm}$ for $15 \mathrm{~min}$. Serum was used for measurements of fasting glucose, lipid profile, serum electrolyte, and fasting serum insulin.

\section{Biochemical Determinations}

A. Fasting glucose and lipid profile were measured using enzymatic colorimetric methods (Cobas Integra 400, Roche Diagnostic, Mannheim, Germany).

B. Low-density lipoprotein cholesterol was calculated using Friedwald's formula [10]: LDL-C $=$ Total Cholesterol (Triglyceride/5 + HDL-C).

C. Serum Electrolyte measurements were carried out by ionselective electrodes using AVL 988 analyzer (Roche Diagnostics, Mannheim, Germany).

D. Serum insulin was measured by enzyme immunoassay using Medgenix-Ins-EASIA kit (BioSource, Belgium) [11].

E. Insulin resistance was calculated with the Homeostasis Model Assessment (HOMA). HOMA was calculated by the formula of Matthews et al., (1985) [12]. HOMA INDEX= Fasting glucose $(\mathrm{mmol} / \mathrm{l}) \mathrm{X}$ Fasting insulin $(\mathrm{uU} / \mathrm{ml}) / 22.5$.

F. Plasma renin activity (PRA) was measured using commercially available solid phase radioimmunoassay kits supplied by Diagnostic Products Corporation (LoS Angeles, CA, USA) according to the manufacture instructions [13].

G. Plasma aldosterone (PA) concentrations were measured using commercially available coat-A-count solid phase radioimmunoassay kits supplied by Diagnostic Products Corporation (Los Angeles, CA, USA), according to the manufacture instructions [14].

\section{Statistical analysis}

Statistical analysis were performed using SPSS software version 15 (SPSS Inc. Chicago, IL). Data were expressed as means \pm SD. Unpaired samples $t$ test was used to compare the mean values in 2 groups. The relationships between variables were assessed using univariate linear regression analysis and Pearson's correlation coefficient. Spearman rank correlations were calculated between PA and PRA according to the number of risk factors. A P value $<0.05$ was accepted as having statistical significance [15].

\section{Results}

Our study included 46 subjects with MSyn and 25 healthy, ageand sex-matched subjects as a control group. Participants' clinical and laboratory data are presented in Table $\mathbf{1}$ and $\mathbf{2}$. There were significant higher levels of plasma aldosterone concentrations, but not plasma renin activity, in MSyn patients than controls and there was no significant difference between both groups regarding serum sodium and potassium. Average HR was significantly increased in MSyn patients compared to controls.

There was significant positive correlation between PA level 
Table 1. Clinical parameters of metabolic syndrome patients and controls.

\begin{tabular}{lccc}
\hline Parameter & $\begin{array}{c}\text { MSyn Patients } \\
(\mathrm{n}=46)\end{array}$ & $\begin{array}{c}\text { Controls } \\
(\mathrm{n}=25)\end{array}$ & P value \\
\hline Age $($ year) & $42.1 \pm 9.40$ & $40.90 \pm 9.78$ & 0.620 \\
Gender (male/female) & $20 / 26$ & $10 / 15$ & 0.327 \\
Current smoking & $24(52.1 \%)$ & $12(48 \%)$ & 0.247 \\
$\begin{array}{l}\text { Waist Circumference } \\
(\mathrm{cm})\end{array}$ & $108.0 \pm 16.0$ & $73.0 \pm 5.48$ & $<0.0001$ \\
BMI $\left(\mathrm{kg} / \mathrm{m}^{2}\right)$ & $32.5 \pm 3.71$ & $22.5 \pm 2.12$ & $<0.0001$ \\
$\begin{array}{l}\text { Systolic blood pressure } \\
(\mathrm{mmHg})\end{array}$ & $156 \pm 14.5$ & $116 \pm 8.16$ & $<0.0001$ \\
$\begin{array}{l}\text { Diastolic blood pressure } \\
(\mathrm{mmHg})\end{array}$ & $95.6 \pm 9.0$ & $75.8 \pm 7.8$ & $<0.0001$ \\
Heart rate (BPM) & $98.7 \pm 12.0$ & $72.3 \pm 6.9$ & 0.024 \\
\hline
\end{tabular}

Table 2. Laboratory parameters of metabolic syndrome patients and controls.

\begin{tabular}{|c|c|c|c|}
\hline Parameters & $\begin{array}{l}\text { MSyn Patients } \\
(\mathrm{n}=46)\end{array}$ & $\begin{array}{l}\text { Controls } \\
(\mathbf{n}=25)\end{array}$ & $P$ value \\
\hline $\begin{array}{l}\text { Fasting blood glucose } \\
(\mathrm{mg} / \mathrm{dl})\end{array}$ & $114.0 \pm 4.66$ & $81.4 \pm 8.01$ & $<0.0001$ \\
\hline $\begin{array}{l}\text { Fasting insulin } \\
(\mathrm{mIu} / \mathrm{ml})\end{array}$ & $14.8 \pm 7.54$ & $6.96 \pm 2.31$ & $<0.0001$ \\
\hline $\begin{array}{l}\text { Insulin resistance } \\
\text { (HOMA-IR) }\end{array}$ & $3.88 \pm 1.94$ & $1.42 \pm 0.52$ & $<0.0001$ \\
\hline $\begin{array}{l}\text { Serum potassium } \\
(\mathrm{mmol} / \mathrm{l})\end{array}$ & $3.93 \pm 0.46$ & $3.84 \pm 0.42$ & 0.440 \\
\hline $\begin{array}{l}\text { Serum sodium } \\
(\mathrm{mmol} / \mathrm{l})\end{array}$ & $140.0 \pm 6.71$ & $138.0 \pm 6.04$ & 0.182 \\
\hline $\begin{array}{l}\text { Total cholesterol } \\
(\mathrm{mg} / \mathrm{dl})\end{array}$ & $197.0 \pm 40.0$ & $127.0 \pm 29.8$ & $<0.0001$ \\
\hline $\begin{array}{l}\text { HDL cholesterol } \\
(\mathrm{mg} / \mathrm{dl})\end{array}$ & $40.4 \pm 4.08$ & $49.6 \pm 5.14$ & $<0.0001$ \\
\hline $\begin{array}{l}\text { LDL cholesterol } \\
(\mathrm{mg} / \mathrm{dl})\end{array}$ & $119.0 \pm 38.0$ & $61.0 \pm 27.8$ & $<0.0001$ \\
\hline $\begin{array}{l}\text { Triglycerides } \\
(\mathrm{mg} / \mathrm{dl})\end{array}$ & $187.0 \pm 32.7$ & $80.9 \pm 21.3$ & $<0.0001$ \\
\hline $\begin{array}{l}\text { Plasma aldosterone } \\
(\mathrm{ng} / \mathrm{dl})\end{array}$ & $6.97 \pm 2.49$ & $5.11 \pm 1.79$ & 0.0016 \\
\hline $\begin{array}{l}\text { Plasma renin activity } \\
\text { (ng.ml-1.h-1) }\end{array}$ & $0.87 \pm 0.26$ & $0.85 \pm 0.22$ & 0.770 \\
\hline
\end{tabular}

and both BMI \& waist circumference and between PA level and both systolic \& diastolic blood pressure. A significant negative correlation was present between PA level and HDL-C but significant positive correlation was present between PA level and s.triglycerides. There was significant positive correlation between PA level and both fasting blood sugar \& insulin resistance (Figures $1 \mathrm{~A}$ to $1 \mathrm{H}$ ).

BMI \& systolic blood pressure were the only independent factors affecting PA level by regression analysis (Table $\mathbf{3}$ ).

In contrast to PRA, PA tended to increase with an increasing number of MSyn risk factors (Figure 2).

\section{Discussion}

Although the role of renin and aldosterone in BP regulation is well known, and high BP is part of the MSyn, less is known about association of renin and aldosterone with the MSyn. Several observations suggest that plasma aldosterone (PA) plays a role in BP regulation in obesity $[16,17]$.

In addition, several studies have reported an association between aldosterone and/or plasma renin activity (PRA) and blood lipids $[18,19]$ and insulin resistance $[20,21]$, which are components of the MSyn. In another words, there is still a conflict about the exact role of PA in the pathogenesis of MSyn and in spite that an activated renin-angiotensinaldosterone system (RAAS) was found to be associated with cardiovascular risk factor clustering [22], no association was found between the MSyn and aldosterone or PRA in a recent TROPHY substudy [21].

The aim of this study was to evaluate the association of PA with the MSyn and each of its components.

In this study, PA was significantly increased in patients with MSyn compared to normal subjects and there was a significant positive correlation between PA and obesity parameters: $\mathrm{BMI}$ and waist circumference. $\mathrm{BMI}$ was the only independent parameter, together with SBP, affecting PA level in multiple regression analysis. It has been demonstrated that obese individuals have activation of the components of the RAAS [23].

On the other hand, weight loss studies demonstrated a significant reduction in aldosterone levels together with renin and angiotensin II, following even moderate weight loss, suggesting the involvement of an increased RAAS activity in the development of obesity hypertension $[16,24]$. Even in normotensive overweight subjects, compared to lean normotensives, Twenty-four hour urinary aldosterone secretion was elevated [25].

PA levels were significantly elevated in MSyn patients, but PRA was not, in our study and in the study of Kidambi et al., 2007 [26] as well. This may reflect a mild variant of primary aldosteronism supports the hypothesis of factors released from fat cells directly or indirectly stimulating aldosterone secretion. In another words, dysfunctional adipose tissue can secrete aldosterone independently from renin stimulation [27].

In our study, heart rate was significantly increased in patients with MSyn compared to normal subjects; may be a marker of absolute or relative sympathetic overactivity. Some reports showed that MSyn is associated with autonomic dysfunction [28], moreover, elevated heart rate has been shown to precede the development of the MSyn [29]. Another study showed that high resting heart rate clusters with other cardiovascular risk factors, such as hypertension, diabetes, and hypertriglyceridemia [30].

Concordant with many studies $[19,31,32]$, our study demonstrated a positive correlation between PA levels and s.triglycerides and a negative correlation between PA levels and high-density lipoprotein (HDL) cholesterol. Some authers [19] demonstrated that patients with the highest aldosterone levels showed the lowest HDL levels. However, 
Abdou et al. Journal of Diabetes Research \& Clinical Metabolism 2013,
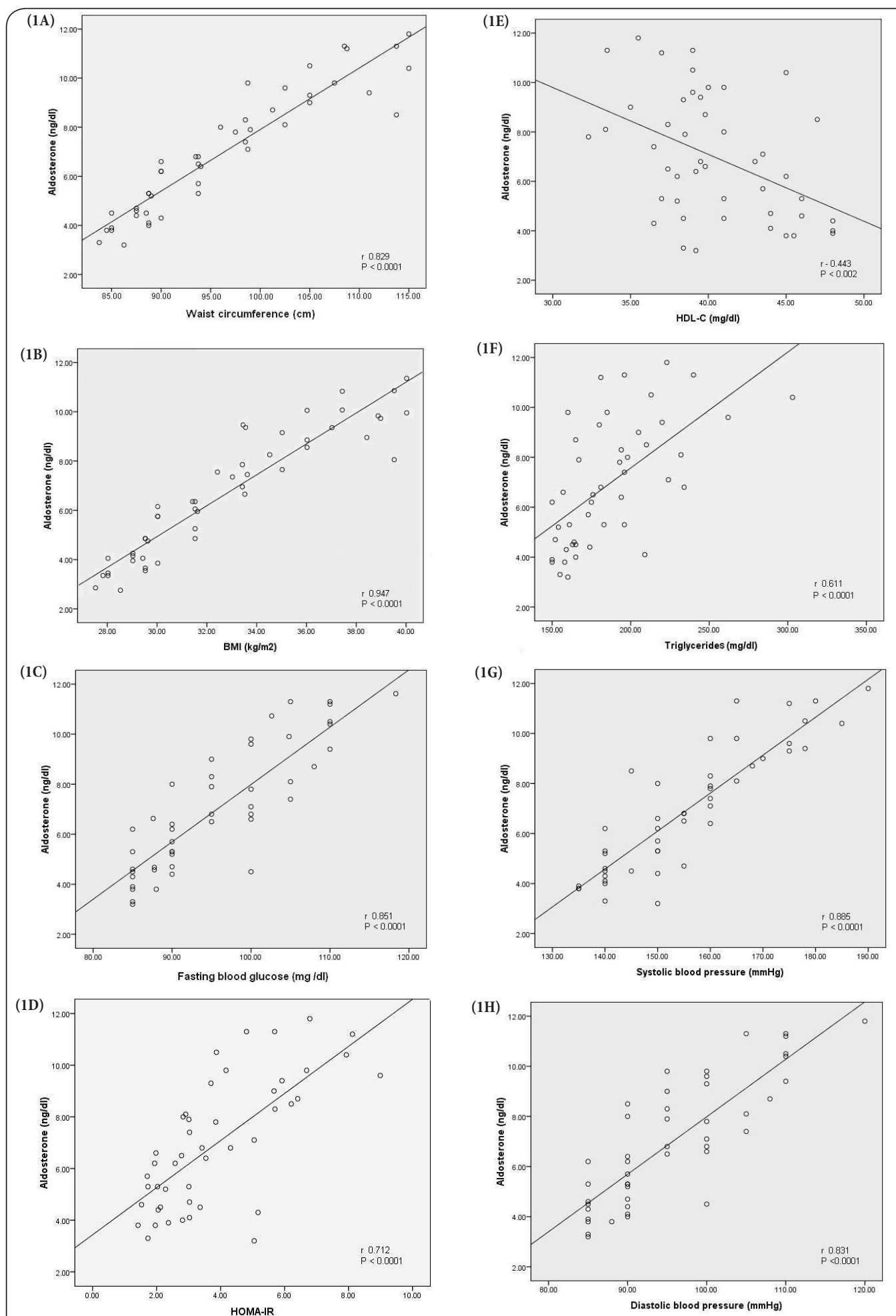

Figure 1A. Correlation between plasma aldosterone level and waist circumference.

1B. Correlation between plasma aldosterone level and body mass index (BMI).

1C. Correlation between plasma aldosterone level and fasting blood glucose.

1D. Correlation between plasma aldosterone level and insulin resistance (IR).

1E. Correlation between plasma aldosterone level and high density lipoprotein-cholesterol (HDL).

1F. Correlation between plasma aldosterone level and S.triglycerides.

1G. Correlation between plasma aldosterone level and systolic blood pressure.

1H. Correlation between plasma aldosterone level and diastolic blood pressure. 
Abdou et al. Journal of Diabetes Research \& Clinical Metabolism 2013, http://www.hoajonline.com/journals/pdf/2050-0866-2-17.pdf

Table 3. Linear regression analysis of the independent factors affecting plasma aldosterone secretion in MSyn patients.

\begin{tabular}{lllll}
\hline & \multicolumn{1}{c}{$\mathbf{b} \pm \mathrm{SE}$} & $\mathbf{t}$ & $\mathbf{P}$ & $\mathrm{Sig}$ \\
\hline Age & $.007 \pm .014$ & .504 & .618 & NS \\
WC & $.000 \pm .020$ & -.016 & .987 & NS \\
FBG & $.014 \pm .067$ & .212 & .833 & NS \\
FI & $-.006 \pm .010$ & -.603 & .551 & NS \\
Cholesterol & $.018 \pm .017$ & 1.042 & .305 & NS \\
Triglycerides & $-.011 \pm .008$ & -1.329 & .193 & NS \\
HDL-C & $-.051 \pm .047$ & -1.106 & .277 & NS \\
LDL-C & $-.017 \pm .016$ & -1.074 & .291 & NS \\
HOMA-IR & $-.003 \pm .128$ & -.022 & .983 & NS \\
PRA & $-.850 \pm .637$ & -1.334 & .192 & NS \\
SBP & $.048 \pm .021$ & 2.309 & .028 & S \\
DBP & $.025 \pm .028$ & .892 & .379 & NS \\
BMI & $.456 \pm .121$ & 3.773 & .001 & S \\
\hline
\end{tabular}

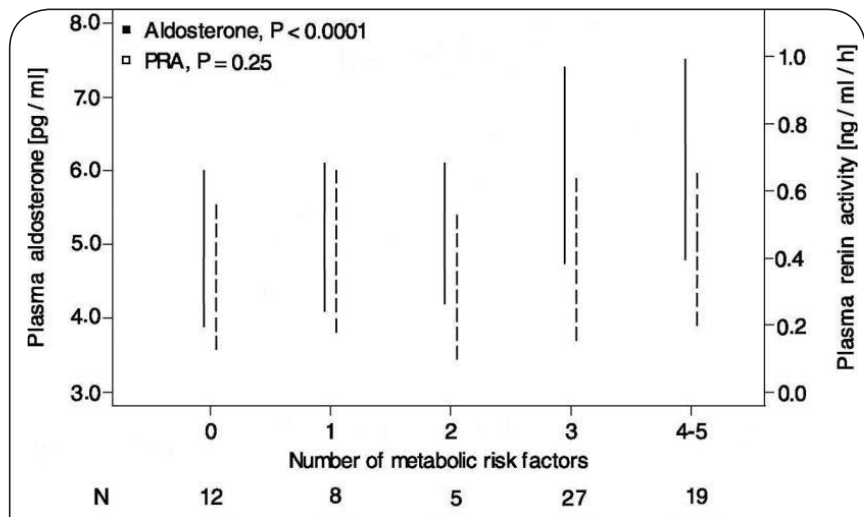

Figure 2. Interrelations of plasma aldosterone and plasma renin activity (PRA) by number of metabolic risk factors.

these patients also presented with the highest BMI suggesting that fat tissue, and not aldosterone, per se, might have caused the derangement in the lipid metabolism. Bochud et al., [31] showed a negative association between plasma aldosterone levels and HDL cholesterol levels in MSyn patients, regardless of all of the other MSyn components. However, a Framingham Heart Study subanalysis with higher subject numbers (2891 subjects) did not show a direct correlation between aldosterone and low HDL cholesterol [32]. Therefore, a possible causative relation between aldosterone and lipid metabolism needs to be investigated further.

Again, SBP was the only independent parameter, together with $\mathrm{BMI}$, affecting PA level in multiple regression analysis and systolic\& diastolic BP were significantly correlated with PA level. The implication of aldosterone in the pathogenesis of arterial hypertension is supported by a vast body of evidence from experimental and clinical studies $[13,33,34]$. Serum aldosterone levels were significantly associated with an elevation of blood pressure in a significant number (1688) of normotensive participants in the Framingham Study, indicating that increased plasma aldosterone levels within the physiological range predispose toward the development of arterial hypertension [34].

Parameters of impaired glucose homeostasis such as fasting plasma glucose, insulin resistance,and insulin levels were significantly affected in patients with MSyn and there were significant correlation between PA level and both insulin resistance and fasting blood glucose. Many observational studies have suggested direct associations between aldosterone levels and parameters of impaired glucose homeostasis in patients with $[21,26]$ and without the MSyn [19]. Besides its classic actions, aldosterone and mineralocorticoid receptor activation affect glucose metabolism, inducing insulin resistance through various mechanisms that involve oxidative stress, inflammation, and downregulation of proteins involved in insulin signaling pathways [35]. However, no conclusive evidence that establishes aldosterone as an independent risk factor for the development of diabetes mellitus and whether aldosterone, per se, on the one hand or elevated blood pressure on the other hand, as a concomitant component of the MSyn with a possible consequence of elevated aldosterone levels is the causative factor for impaired glucose homeostasis [36].

Inspite of missing salt loading or suppression tests to confirm the presence of 1 ry aldosteronism, we supposed that our patients lack this abnormality in the presence of normal s.potassium, stage- 1 hypertension at most, and the non-significant difference between both controls and MSyn patients regarding PRA. There was a strong relation between $\mathrm{PA}$, but not PRA, with the numbers of risk factors. In conclusion, PA is associated with MSyn and its components, although an association does not necessarily imply a cause-effect relationship.These findings reinforce previous observations suggesting that aldosterone is associated with several cardiovascular risk factors. Additional studies are needed to determine the role of aldosterone in causing metabolic dysfunction and to address the possible beneficial effects of aldosterone blockade in MSyn patients.

\section{List of abbreviations}

BMI: Body Mass Index

BP :Blood Pressure

DBP: Diastolic Blood Pressure

FBG: Fasting Blood Glucose

FI: Fasting Insulin

HDL-C: High Density Lipoprotein Cholesterol

HOMA-IR: HOmeostasis Model Assessment-Insulin Resistance HR: Heart Rate

LDL-C: Low Density Lipoprotein Cholesterol

MSyn: Metabolic Syndrome

PRA: Plasma Renin Activity

PA: Plasma Aldosterone

SBP: Systolic Blood Pressure

WC: Waist Circumference 


\section{Competing interests}

The authors declare that they have no competing interests.

\section{Publication history}

Received: 08-Feb-2013 Revised: 04-Mar-2013

Accepted: 06-Mar-2013 Published: 29-Mar-2013

\section{References}

1. Ginsberg HN and MacCallum PR: The obesity, metabolic syndrome, and type 2 diabetes mellitus pandemic: Part I. Increased cardiovascular disease risk and the importance of atherogenic dyslipidemia in persons with the metabolic syndrome and type 2 diabetes mellitus. J Cardiometab Syndr 2009, 4:113-9. | Article | PubMed Abstract | PubMed Full Text

2. Briet $M$ and Schiffrin EL: The role of aldosterone in the metabolic syndrome. Curr Hypertens Rep 2011, 13:163-72. | Article | PubMed

3. Mottillo S, Filion KB, Genest J, Joseph L, Pilote L, Poirier P, Rinfret $\mathrm{S}$, Schiffrin EL and Eisenberg MJ: The metabolic syndrome and cardiovascular risk a systematic review and meta-analysis. J Am Coll Cardiol 2010, 56:1113-32. | Article | PubMed

4. Stas S, Whaley-Connell AT and Sowers JR: Aldosterone and hypertension in the cardiometabolic syndrome. J Clin Hypertens (Greenwich) 2008 , 10:94-6. | Article | PubMed

5. Stiefel P, Vallejo-Vaz AJ, Garcia Morillo S and Villar J: Role of the ReninAngiotensin system and aldosterone on cardiometabolic syndrome. Int J Hypertens 2011, 2011:685238. | Article | PubMed Abstract | PubMed Full Text

6. Third Report of the National Cholesterol Education Program (NCEP) Expert Panel on Detection, Evaluation, and Treatment of High Blood Cholesterol in Adults (Adult Treatment Panel III) final report. Circulation 2002, 106:3143-421. | Article | PubMed

7. The World Medical Association Ethics Unit. Declaration of Helsinki. [5 November 2003]

8. Statistics Canada. Canadian Health Measures Survey (CHMS) Data User Guide: Cycle 2,September 2012. I Website

9. National Institutes of Health. The Practical Guide to the Identification, Evaluation and Treatment of Overweight and Obesity in Adults. Bethesda, Maryland: National Institutes of Health, 2000.

10. Friedewald WT, Levy RI and Fredrickson DS: Estimation of the concentration of low-density lipoprotein cholesterol in plasma, without use of the preparative ultracentrifuge. Clin Chem 1972, 18:499-502. Article I PubMed

11. Frier BM, Ashby JP, Nairn IM and Baird JD: Plasma insulin, C-peptide and glucagon concentrations in patients with insulin-independent diabetes treated with chlorpropamide. Diabete Metab 1981, 7:45-9. | Article | PubMed

12. Matthews DR, Hosker JP, Rudenski AS, Naylor BA, Treacher DF and Turner RC: Homeostasis model assessment: insulin resistance and beta-cell function from fasting plasma glucose and insulin concentrations in man. Diabetologia 1985, 28:412-9. | Article | PubMed

13. Carillo BA, Beutel A, Mirandola DA, Vidonho AF, Jr., Furukawa LN, Casarini D, Campos RR, Dolnikoff MS, Heimann JC and Bergamaschi $\mathrm{CT}$ : Differential sympathetic and angiotensinergic responses in rats submitted to low- or high-salt diet. Regul Pept 2007, 140:5-11. | Article I PubMed

14. Brown NJ, Nakamura S, Ma L, Nakamura I, Donnert E, Freeman M, Vaughan DE and Fogo AB: Aldosterone modulates plasminogen activator inhibitor-1 and glomerulosclerosis in vivo. Kidney Int 2000, 58:1219-27. | Article | PubMed

15. Knapp RG, Miller MC: Describing the performance of a diagnostic test. In: Clinical epidemiology and biostatistics. Baltimore, Williams \& Wilkins 1992, p.31-45

16. Engeli S, Bohnke J, Gorzelniak K, Janke J, Schling P, Bader M, Luft FC and Sharma AM: Weight loss and the renin-angiotensin-aldosterone system. Hypertension 2005, 45:356-62. | Article | PubMed

17. Goodfriend TL, Egan BM and Kelley DE: Aldosterone in obesity. Endocr Res 1998, 24:789-96. | Article | PubMed

18. Goodfriend TL, Egan BM and Kelley DE: Plasma aldosterone, plasma lipoproteins, obesity and insulin resistance in humans. Prostaglandins Leukot Essent Fatty Acids 1999, 60:401-5. I Article I PubMed

19. Goodfriend TL, Egan B, Stepniakowski K and Ball DL: Relationships among plasma aldosterone, high-density lipoprotein cholesterol, and insulin in humans. Hypertension 1995, 25:30-6. I Article I PubMed

20. Goodfriend TL, Kelley DE, Goodpaster BH and Winters SJ: Visceral obesity and insulin resistance are associated with plasma aldosterone levels in women. Obes Res 1999, 7:355-62. | Article | PubMed

21. Egan BM, Papademetriou V, Wofford M, Calhoun D, Fernandes J, Riehle JE, Nesbitt S, Michelson E and Julius S: Metabolic syndrome and insulin resistance in the TROPHY sub-study: contrasting views in patients with high-normal blood pressure. Am J Hypertens 2005, 18:3-12. | Article | PubMed

22. Egan BM, Stepniakowski K and Goodfriend TL: Renin and aldosterone are higher and the hyperinsulinemic effect of salt restriction greater in subjects with risk factors clustering. Am J Hypertens 1994, 7:886-93. | Article | PubMed

23. Sharma AM: Is there a rationale for angiotensin blockade in the management of obesity hypertension? Hypertension 2004, 44:12-9. | Article I PubMed

24. Ho JT, Keogh JB, Bornstein SR, Ehrhart-Bornstein M, Lewis JG, Clifton PM and Torpy DJ: Moderate weight loss reduces renin and aldosterone but does not influence basal or stimulated pituitary-adrenal axis function. Horm Metab Res 2007, 39:694-9. | Article I PubMed

25. Bentley-Lewis R, Adler GK, Perlstein T, Seely EW, Hopkins PN, Williams $\mathrm{GH}$ and Garg R: Body mass index predicts aldosterone production in normotensive adults on a high-salt diet. J Clin Endocrinol Metab 2007, 92:4472-5. | Article | PubMed

26. Kidambi S, Kotchen JM, Grim CE, Raff H, Mao J, Singh RJ and Kotchen TA Association of adrenal steroids with hypertension and the metabolic syndrome in blacks. Hypertension 2007, 49:704-11. | Article | PubMed

27. Hajer GR, van Haeften TW and Visseren FL: Adipose tissue dysfunction in obesity, diabetes, and vascular diseases. Eur Heart J 2008, 29:2959-71. I Article I PubMed

28. Grassi G and Seravalle G: Autonomic imbalance and metabolic syndrome: unravelling interactions, mechanisms and outcomes. $J$ Hypertens 2006, 24:47-9. | Article | PubMed

29. Tomiyama H, Yamada J, Koji Y, Yambe M, Motobe K, Shiina K, Yamamoto $Y$ and Yamashina A: Heart rate elevation precedes the development of metabolic syndrome in Japanese men: a prospective study. Hypertens Res 2007, 30:417-26. | Article | PubMed

30. Inoue T, Oshiro S, Iseki K, Tozawa M, Touma T, Ikemiya Y and Takishita S: High heart rate relates to clustering of cardiovascular risk factors in a screened cohort. Jpn Circ J 2001, 65:969-73. | Article | PubMed

31. Bochud M, Nussberger J, Bovet P, Maillard MR, Elston RC, Paccaud F, Shamlaye $C$ and Burnier M: Plasma aldosterone is independently associated with the metabolic syndrome. Hypertension 2006, 48:239-45. | Article | PubMed

32. Kathiresan S, Larson MG, Benjamin EJ, Corey D, Murabito JM, Fox CS, Wilson PW, Rifai N, Meigs JB, Ricken G, Lifton RP, Levy D and Vasan RS: Clinical and genetic correlates of serum aldosterone in the community: the Framingham Heart Study. Am J Hypertens 2005, 18:657-65. I Article I PubMed

33. Stewart PM: Mineralocorticoid hypertension. Lancet 1999, 353:1341-7. Article | PubMed

34. Vasan RS, Evans JC, Larson MG, Wilson PW, Meigs JB, Rifai N, Benjamin EJ and Levy D: Serum aldosterone and the incidence of hypertension in nonhypertensive persons. N Engl J Med 2004, 351:33-41. | Article | PubMed

35. Briet $\mathrm{M}$ and Schiffrin EL: The role of aldosterone in the metabolic syndrome. Curr Hypertens Rep 2011, 13:163-72. | Article | PubMed

36. Krug AW and Ehrhart-Bornstein M: Aldosterone and metabolic syndrome: is increased aldosterone in metabolic syndrome patients an additional risk factor? Hypertension 2008, 51:1252-8. | Article | PubMed

\section{Citation:}

Abdou M, AbdElGawad M S and Mohamed S A: Increased aldosterone in patients with metabolic syndrome; an additional risk factor. Journal of Diabetes Research and Clinical Metabolism 2013, 2:17. http://dx.doi.org/10.7243/2050-0866-2-17 